\title{
Tongue soles revised
}

from our Marine Vertebrate Correspondent

THE flatfishes are an interesting and important group of bony fishes: interesting because of their unique asymmetry which involves a complicated reordering of the head skeleton, eyes and optic nerves on metamorphosis; important because almost throughout the world they are of considerable value as food fishes. These two aspects have resulted in their being studied by workers in different disciplines possibly more than most comparably sized fish groups. Their systematic arrangement and taxonomy have been studied, notably by Norman in his Systematic Monograph of Flatfishes 1 (London, 1934) although he never completed the second volume which was to have included the families of true soles and tongue soles (Soleidae and Cynoglossidae).

To some extent this hiatus has partly been filled by a comprehensive revision of the tongue soles of the genus Cynoglossus by A. J. K. Menon (Smithsonian Contributions to Zoology, no. 238, $1-129 ;$ 1977). The Cynoglossidae are flatfishes which have a typical elongate body form, tongue sole being a most apt name. The dorsal, caudal, and anal fins are continuous around the edge of the body, other fins are reduced or absent, and the mouth is placed on the side of the head, in most species having a sinister curve about it. In the genus Cynoglossus the eyes are very small, close together and are always on the left side of the head. It seems that the reduction of the eyes is probably associated with the well-developed lateral line sensory system; in some species three lateral lines run along the length of the body while most have a complex of head lines. On the blind side, however; this sensory system is reduced or totally absent (a striking difference to the situation in the true soles which have a highly evolved sensory system on the eyeless side of the head). As Menon points out members of the Soleidae are mostly feeders on the surface of the sea bed, while the tongue soles are adapted to plough through the mud or sand on the bottom, hidden beneath the surface themselves, and feeding on buried food organisms.

factors in arid and tropical countries -and so make it difficult in parts of northern Europe to devise reference curves for trees such as oak, beech and elm which all react differently to environmental conditions. In northern Europe too there is the added disadvantage that no tree has the lon-
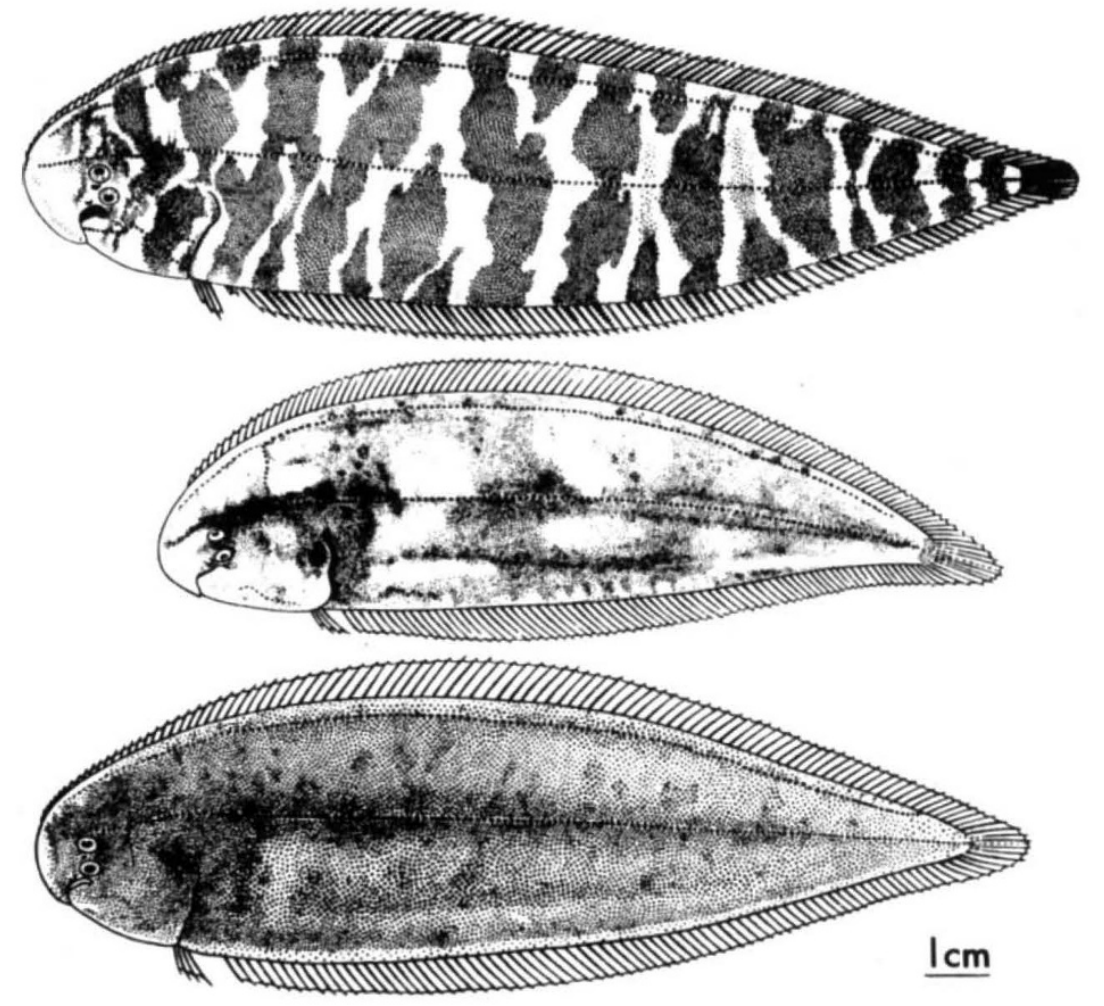

Three specimens of $C$. puncticeps showing variation in pigment pattern. Top from Kerala; others from Cochin.

As an adaptation to this way of life the these tongue soles has a number of cynoglossids do not have the fin rays of points of interest. The centre of distrithe dorsal fin running forward to the bution lies in the eastern Indian Oceanextreme edge of the head (as do the West Pacific area, especially around the soles) but the first dorsal pterygiophore, Malay archipelago, where Menon finds which in other fish would support the the more specialised and rapidly evolvanterior fin rays, is modified to form ing species complexes. Around the peria rostral cartilage. This rostral cartilage phery of this region more primitive provides support for the thin, elongate types are found, ranging from Japan to snout which acts like a forward- eastern Australia, and along the Indian pointing ploughshare as the fish slices Ocean coast of Africa. Cynoglossus is its way through the seabed.

Menon's revisionary study is, of course, basically a systematic work. He gives a brief discussion of the other genera in the family (Symphurus with forty or so species, Paraplagusia with only four species), and then detailed diagnoses of the forty-nine members of the genus Cynoglossus. All the species are illustrated by simple line drawings supplemented by photographs of most species. Menon's work thus means that in the future there will be an adequate source of identification available for these closely similar fishes.

The geographical distribution of one of the few groups of fishes which are widespread in the Indo-Pacific and are found off the West African coast as well, although absent in the Western Atlantic. Most of the West African species belong to a large group of species (the canariensis group) which Menon regards as primitive and near to the ancestral stock. Menon's study thus has some interest in the evolution of this group of flatfishes and will be of value to zoogeographic studies although work in a broader field than at generic level will be necessary to evaluate some of his conclusions concerning relationships and distribution. gevity of the bristle-cone pine or sequoia although sessile oaks often live more than 500 years. Oak is the timber found most often in archaeological excavations.

Although the Russian, Shvedov, as long ago as 1892 , related variations in annual ring width to rainfall, it was the German, Huber, who from the 1940 s to his death in 1970 , laid the foundations of the modern methodology and his influence remains in the rigorous work of $\mathrm{J}$. Bauch and $\mathrm{D}$. Ekstein (University of Hamburg) and B. Becker (University of Hohenheim) which sets standards for all other 